\title{
Review of field experiences: Integration of family planning and PMTCT services
}

\author{
Naomi Rutenberg \\ Population Council \\ Carolyn Baek \\ Population Council
}

Follow this and additional works at: https://knowledgecommons.popcouncil.org/departments_sbsr-hiv

Part of the Demography, Population, and Ecology Commons, Health Policy Commons, Immune System Diseases Commons, International Public Health Commons, Maternal and Child Health Commons, Medicine and Health Commons, Public Health Education and Promotion Commons, Virus Diseases Commons, and the Women's Health Commons How does access to this work benefit you? Let us know!

\section{Recommended Citation}

Rutenberg, Naomi and Carolyn Baek. 2004. "Review of field experiences: Integration of family planning and PMTCT services," Horizons Final Report. Washington, DC: Population Council. 
This "Review of Field Experiences: Integration of Family Planning and PMTCT Services" was commissioned from the Population Council by the World Health Organization (WHO) as an input into a WHO/UNFPA sponsored consultative meeting on The linkages between reproductive health and HIV/AIDS: Family planning and prevention of mother of child transmission, held in Montreux, Switzerland, May 3-4, 2004. 


\title{
Review of Field Experiences: \\ Integration of Family Planning and PMTCT Services
}

\author{
Naomi Rutenberg \\ Carolyn Baek
}

April 2004

(2) Population Council 


\section{TABLE OF CONTENTS}

Introduction $\quad 4$

Objectives, Activities, and Methods of Review 4

Availability and Provision of Family Planning $\quad 6$

Community and Individual Opinions about HIV-positive Women and Childbearing 13

Demand for Family Planning Among HIV-positive Women 15

Use of Family Planning Among PMTCT Clients 17

Integration of Family Planning and PMTCT Services 20

Challenges to Prioritizing Family Planning as a PMTCT Service 25

$\begin{array}{ll}\text { Conclusions/Recommendations } & 30\end{array}$

$\begin{array}{ll}\text { References } & 34\end{array}$

Figures, Tables and Boxes

Figure 1 Percent of PMTCT clients who received antenatal and postpartum $\quad 8$ family planning counseling in Lusaka, Zambia

Figure 2 Percent of observed family planning sessions in Uganda in which HIV 25

Table $1 \quad$ Percent of PMTCT clients who received antenatal and postpartum $\quad 9$ family planning counseling on day of interview at two sites in Kenya, by HIV status

Table 2 Postnatal clients' views on good family planning methods for HIV- 17

Table 3 Percent of use and non-use of family planning of PMTCT clients at $6 \quad 18$ months postpartum, by HIV status

Table 4 Percent of condom use with partner/spouse 9-12 months postpartum, 19

Box 1 Sites run by faith-based organizations provide limited family planning 12

Appendices

Appendix A Questionnaires 35

$\begin{array}{lll}\text { Appendix B } & \text { List of interviewees } & 38\end{array}$ 


\section{Acknowledgements}

We would like to acknowledge the contributions of the many people who made this report possible. The appendix lists the names of individuals who kindly shared their time and experiences with us. We would like to thank Peter Omondi and Grace Muthumbi in Kenya, Linda Andrews in Uganda, and Martha Butler and Virginia Salcedo in the Dominican Republic for helping to set up site visits and interviews. We would also like to thank Thomas and Edith Welty and Maxine Eber for connecting us with their colleagues in Cameroon and Uganda respectively. Finally, we would like to acknowledge our colleagues who gathered data: Simon Baker, Magda Chinaglia, Milka Juma, Susan Kaai, and Vaishali Mahendra.

Financial support for this review was provided by the World Health Organization (WHO) through a Memorandum of Understanding between the WHO and the Population Council (HQ/04/138302).

The Population Council is an international, nonprofit, nongovernmental institution that seeks to improve the wellbeing and reproductive health of current and future generations around the world and to help achieve a humane, equitable, and sustainable balance between people and resources. The Population Council conducts biomedical, social science, and public health research and helps build research capacities in developing countries. Established in 1952, the Population Council is governed by an international board of trustees. Its New York headquarters supports a global network of regional and country offices. 


\section{INTRODUCTION}

Preventing unintended pregnancy among HIV-positive women through family planning services is one of the four cornerstones of a comprehensive program for prevention of mother-to-child HIV transmission (PMTCT) (WHO 2002). ${ }^{1}$ Reducing unintended pregnancies among HIV-positive women through family planning reduces the number of children potentially orphaned when parents die of AIDS-related illnesses. It also reduces HIV-positive women's vulnerability to morbidity and mortality related to pregnancy and lactation. In addition, family planning for both HIV-positive and -negative women safeguards their health by enabling them to space births.

The global public health community-NGOs, governments, and international donorshas mobilized to design and provide essential PMTCT services: voluntary counseling and testing (VCT), infant feeding counseling, outreach to communities and families, and a short course of antiretroviral therapy. In most cases, the implementation approach has been to incorporate PMTCT into services that already reach pregnant women and women of childbearing age: antenatal care, obstetrical care, and maternal/child health. Yet the complexity of introducing PMTCT into the real world - that is, existing health services in resource-poor settings-soon became clear. Population Council and its research partners have been addressing several key questions about PMTCT services and how well they function in field settings. This report reviews field experiences with the integration of family planning and PMTCT services. It is hoped that this review will provide evidence and information for developing effective strategies for appropriately promoting family planning within PMTCT programs.

\section{OBJECTIVES, ACTIVITIES, AND METHODS OF REVIEW}

The World Health Organization asked the Population Council to provide a review of field experiences regarding the integration of family planning and PMTCT services. This information would help set the stage for an international meeting about family planning and PMTCT in May 2004.

The timeframe for the review was brief. Population Council carried out this review from February - March 2004 in consultation with the WHO and USAID. The following describe activities completed and methodologies used.

- Tabulation and analysis of data covering topics such as the availability of services, extent and effect of integration of family planning and PMTCT, and attitudes about and use of family planning by PMTCT clients from Horizons ${ }^{2}$

\footnotetext{
${ }^{1}$ The other three cornerstones are primary prevention of HIV infection in women, reducing transmission from HIV infected pregnant and lactating women to their children, and the care and support of women, infants, and families infected and affected by HIV/AIDS.

${ }^{2}$ Horizons is a global HIV/AIDS operations research program of USAID's Global Bureau. The lead agency for Horizons is Population Council, and its partners are International Center for Research on Women (ICRW), Program for Appropriate Technology for Health (PATH), International HIV/AIDS Alliance, Tulane University, Family Health
} 
operations research studies in Kenya, Uganda, and Zambia. Also, results from Population Council's evaluation of UN supported sites were incorporated. ${ }^{3}$

- Questionnaires were developed to interview international and national program managers, and site managers and providers. Please see Appendix A for the questionnaires.

- Face-to-face or telephone interviews with international program managers from institutions such as UNFPA, Elizabeth Glaser Pediatric AIDS Foundation, and Family Health International. A list of international program managers interviewed is found in Appendix B.

- Face-to-face or telephone interviews with national level program managers and stakeholders in Africa, Latin America/Caribbean, and Asia. Cameroon, Kenya, Namibia, South Africa, Uganda, Brazil, the Dominican Republic, India, and Thailand were selected based on three criteria: desire to represent different regions of the world; variability in HIV and contraceptive prevalence; and feasibility of conducting interviews in a short period of time. There is a variation in the number of interviews per country with more national level stakeholders interviewed in countries where site visits were also completed. Please see Appendix B for the list of national level stakeholders who were interviewed.

- Site visits and interviews with site managers and providers in Kenya, Uganda, the Dominican Republic, India, and Thailand. Please see Appendix B for the list of individuals who agreed to be interviewed. One individual from Population Council conducted site visits in each country, and the time spent undertaking site visits was 2-3 days. In each country, 2-3 sites were visited and at each site generally 1-3 providers were interviewed. Sites were selected on the basis of feasibility given time and resource constraints. For instance, many of the sites visited are either in the capital city or near it. Others are sites where there is ongoing Horizons research. Observations from these sites are not meant to be

International (FHI), and Johns Hopkins University. The purpose of Horizons is to conduct operations research to identify components of effective HIV/AIDS programs and policies. An integral part of the Horizons approach to operations research is disseminating findings to policy makers and program managers, with a view of replicating and scaling up successful interventions.

${ }^{3}$ The following provides more detail about the Horizons studies mentioned in this report. In Kenya and Zambia, Horizons collaborated with NARESA and the MTCT Working Group, respectively, and UNICEF to document the acceptability, operational barriers, costs, and impact of pilot PMTCT services. The major research activities in each country included tracking the utilization of various services, including VCT and family planning; following a cohort of clinic users for 12 to 18 months to determine the effect of PMTCT service utilization on knowledge, practices, and rates of mother-to-child HIV transmission; observation of the quality of care delivered by providers; and an economic analysis of the PMTCT program. In Uganda, Horizons collaborated with AIDS Information Center, AIDS Control Program, and Makarere Institute of Social Research to test a strategy for the integration of HIV counseling into health services, including family planning. In the Uganda study, researchers used a combination of methods to determine the extent to which providers assessed client needs, discussed HIV-related issues, and made referrals for such related services as VCT. Finally in the UN study, the 11 countries that were part of the evaluation were Botswana, Burundi, Honduras, India, Ivory Coast, Kenya, Rwanda, Tanzania, Uganda, Zambia, and Zimbabwe. UNICEF and Population Council employed a mix of qualitative and quantitative methodologies, including a rapid assessment of services at pilot sites in Rwanda and Zambia, to identify strengths as well as gaps in service delivery (see Rutenberg et al. 2003). 
representative of a country's experience with family planning and PMTCT. They are examples of what activities are happening on the ground as well as different types of service delivery and service delivery organizations.

- Either detailed or verbatim notes were taken from these interviews, and were collated for review and analysis.

\section{FINDINGS}

\section{AVAILABILITY AND PROVISION OF FAMILY PLANNING}

Family planning is a standard component of PMTCT programs and is offered either within or adjacent to the same building as other PMTCT services. Family planning counseling and education is provided during antenatal care while family planning counseling and methods are offered postnatally.

Without exception, family planning has been adopted as one of the elements of national PMTCT programs though the content, intensity, and degree of integration varies considerably between national programs and also between sites within a program.

During the evaluation of UN-supported sites, program managers were asked if family planning services were provided as part of the PMTCT program. Program managers at the national level in all 11 countries responded that family planning services were indeed part of their PMTCT program, which was centered within ANC/MCH services. Sites visited in Kenya, Uganda the Dominican Republic, India, and Thailand corroborated that family planning services are provided. Moreover, family planning services are offered in the same building or very close by to other PMTCT services. In terms of when family planning counseling and services were given, sites tended to offer counseling and education in ANC while counseling and methods were offered postnatally, either immediately after delivery or 4-6 weeks postpartum.

In Uganda, providers at three health facilities discussed how family planning counseling is first introduced during ANC in group talks. Women learn about the range of services offered in the clinic, including family planning. Providers at different sites emphasized the importance of continuous family planning counseling throughout ANC, saying "we give family planning information and counseling every time the mothers come for ANC..." and "family planning counseling is given during every antenatal visit. We give the information repetitively because it is not picked or acted upon immediately. People implement what they have learnt slowly". Providers reported that actual methods are offered at 6 weeks postpartum, yet a program manager stressed how most women do not return to health facilities for postnatal visits. ${ }^{4}$ At two out of the three sites, family

\footnotetext{
4 The most recent DHS indicates that $63 \%$ of women in Uganda do not deliver at a health facility. Of these women, $92 \%$ have not accessed postnatal care as defined by going to a health facility within 41 days after delivery. Moreover, the Uganda contraceptive prevalence rate is low, with less than a fifth of married women using a modern method.
} 
planning services are in the same building as PMTCT services. At the third facility, it is located about 80 meters away. One provider indicated that patients were escorted to this nearby clinic while another expressed the desire for reorganization of services so that "a PMTCT mother" did not have to be referred.

At a hospital in Kenya, family planning services are offered at 4-6 weeks after delivery when the woman has come for a postnatal check up. In one visit, she has opportunities to receive consultations about her clinical care, and care for her infant including information about feeding, and family planning. She also can participate in the post test club. Temporarily, family planning is being carried out in the same building. It was previously offered in an adjacent clinic, which was closed and made into a SARS center. According to one of the providers interviewed, "This was a blessing in disguise. It has worked so well with us and it is really convenient for us and we see it as a model for integrating family planning and PMTCT." Her comment suggests the benefit of having all the PMTCT related services in the same building, while another provider spoke about how family planning being placed in the same building could lead to overcrowding. At an NGO clinic where family planning services are in the same building, providers explained that family planning counseling is done in ANC and then counseling and methods are offered at the 6 weeks postnatal visit. "Those mothers who come to the clinic after they have delivered, we remind them about family planning. So far all of our PMTCT clients turn up on this first postnatal clinic visit [at 6 weeks]."

However, international program managers involved in PMTCT programs in sub-Saharan Africa point out that they have seen many facilities in which postnatal follow up is very difficult. Women are not generally coming back to facilities for postnatal care, including family planning counseling and services. Moreover, with respect to family planning counseling during ANC, typically there is not a lot of counseling done because providers lack time. Also, in light of the fact that women are discovering their HIV status during ANC, issues such as understanding and accepting their test result and its implications understandably far outweigh any family planning concerns. One individual remarked that, "I'm not sure how much family planning counseling is done by ANC providers nursing staff are overworked and overburdened by patient care.... And in relation to the counselors, my impression is that counselors focus on the pre and post test counseling cycle, with few mothers having the opportunity to visit counselors during ANC for a second visit, which means it is unlikely that there is a discussion about family planning."

At both the hospitals in the Dominican Republic, family planning counseling and services are provided in the same building as PMTCT services. Family planning counseling/education also begins at ANC group talks, which women attend during their first ANC visit. But from post test counseling onwards, family planning is discussed in markedly different ways depending on HIV status. For HIV-negative patients, they are encouraged to stay negative, are offered family planning methods immediately after delivery, as well as standard family planning services at the family planning clinic postpartum. For HIV-positive women, they are introduced to the option of sterilization, which is completed immediately after elective caesarean. At one site, the head of the 
PMTCT program explained that sterilization could also be completed 10 days after delivery.

While the interviews in Thailand did not go into great detail about family planning organization, providers at the three hospitals visited explained that family planning counseling and services are provided in the same building as PMTCT services. Patients hear about family planning during ANC and then are offered additional counseling and services postnatally. Providers explained further that women could ask questions about or access family planning services anytime they wished. Family planning services are very much considered part of the PMTCT program.

\section{PMTCT sites miss opportunities to provide clients with family planning counseling.}

Although family planning counseling is provided at various points during the period that women attend ANC/MCH services, data from Horizons studies show many missed opportunities to provide PMTCT clients with family planning counseling. In Lusaka, Zambia, slightly more than a third of the pregnant clients received family planning counseling during their antenatal visit that day (see Figure 1). Most women had not taken an HIV test and did not know their serostatus. Among those re-interviewed at their threemonth postpartum visit (37 percent of the women originally interviewed), a greater proportion of women received family planning counseling. More than half of HIVpositive and -negative women discussed family planning with the provider on that day. Attention to family planning decreased slightly at the six-month postpartum visit: 38 percent of HIV-positive women discussed family planning, while 50 percent of HIVnegative women did so.

Figure 1 Percent of PMTCT clients who received antenatal and postpartum family planning counseling in Lusaka, Zambia

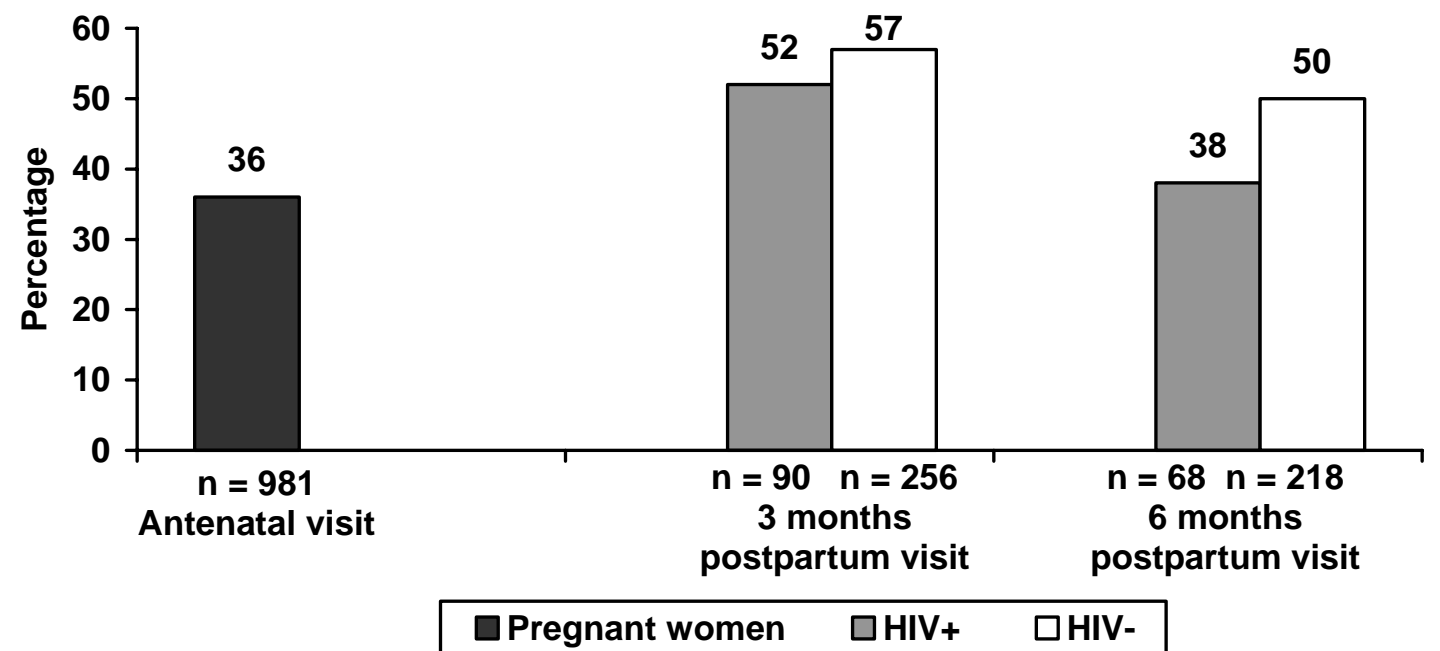

At the two Kenya PMTCT sites, more than one-fifth of women reported that they engaged in a discussion about family planning during their antenatal visit on the day of the interview, but few women in the cohort study subsequently reported receiving any 
postpartum counseling on this topic (see Table 1). In Karatina, Kenya, many of the women interviewed were using injectable contraceptives and may have been experienced family planning users; thus, they may have mainly seen family planning providers to continue their already chosen method. Interviews were also timed to coincide with immunization visits, and women may not have needed or sought out family planning counseling on these days.

Table 1 Percent of PMTCT clients who received antenatal and postpartum family planning counseling on day of interview at two sites in Kenya, by HIV status

\begin{tabular}{|c|c|c|c|c|c|c|}
\hline & \multicolumn{2}{|c|}{ Antenatal } & \multicolumn{2}{|c|}{$\begin{array}{l}3 \text { months } \\
\text { postpartum }\end{array}$} & \multicolumn{2}{|c|}{$\begin{array}{c}6 \text { months } \\
\text { postpartum }\end{array}$} \\
\hline & $\%$ & $\mathbf{n}$ & $\%$ & $\mathbf{n}$ & $\%$ & $\mathbf{n}$ \\
\hline \multicolumn{7}{|c|}{ Homa Bay } \\
\hline $\mathrm{HIV}_{+}$ & 29 & 212 & 0 & 72 & 0 & 62 \\
\hline HIV- & 23 & 380 & 2 & 173 & 1 & 163 \\
\hline \multicolumn{7}{|l|}{ Karatina } \\
\hline $\mathrm{HIV}_{+}$ & 21 & 89 & 0 & 32 & 3 & 37 \\
\hline HIV- & 22 & 911 & 2 & 310 & 0 & 236 \\
\hline
\end{tabular}

In all three of these sites there is a similar proportion of HIV-positive and -negative women who received (or did not receive) family planning counseling. This suggests that providers are not specifically targeting HIV-positive women with family planning messages.

A variety of providers carry out family planning counseling and services. At some sites, the same providers give both family planning and PMTCT services.

There is a range of providers who give family planning counseling and services. In Thailand and Kenya, nurses and counselors carry out family planning. (In Kenya, nurses provide family planning at the hospital site in Nairobi while at the NGO clinic in Kibera, nurses and counselors provide these services. However, it was specified at the clinic that counselors who had not been trained in family planning can only give pills.) In addition to nurses and counselors, in Uganda midwives were also reported to give family planning. The Dominican Republic had the greatest range of family planning providers. Doctors, nurses, nurse assistants, psychologists, health educators, and volunteers were cited as possible providers.

When asked if the same provider delivers PMTCT as well as family planning services, the responses ranged from the same providers to partial overlap. In Thailand and the Dominican Republic (which were both hospital settings), the same multidisciplinary 
team provides family planning counseling and services. In Kenya, at the NGO clinic, it is the same nurses and counselors who give family planning services. But service organization is different at the hospital in that while there is some overlap, it is not fully the same group of individuals. At the hospital, one of the providers indicated that "it is only nurses who have been trained in PMTCT that deliver both services. Currently we are planning to conduct a big PMTCT training for all nurses and doctors in our ANC clinic so that all our staff can know how to handle our positive clients." Another provider responded, "yes, but some family planning nurses are yet to be trained on MTCT so that all of them should be able to offer PMTCT and family planning to the infected mothers." Within this relatively high prevalence environment, these responses suggest that providers perceive the need for training on HIV issues in order to provide comprehensive family planning services.

While two sites in Uganda are similar to those described above, at one site, the service organization is different. Family planning counseling begins at ANC as part of the PMTCT program. Women are then referred to the family planning clinic, and receive further counseling and then services by family planning providers.

\section{Sites visited as part of review show that health facilities offer a range of methods.}

Sites visited in Kenya, Uganda, the Dominican Republic, India, and Thailand carry several different methods of contraceptives, with many of them having permanent in addition to temporary methods. Examples of methods offered at sites include pill, condom, injectable, implant, IUD, and tubal ligation. The variety of methods offered at these sites may be attributed to the fact that many of the sites visited are hospitals and clinics in urban settings. A program manager in Cameroon discussed how clinics in rural settings can have extremely limited variety of commodities, and that this was a contributing factor to minimal offering of family planning counseling and services.

\section{Contraceptive stock outs are a problem to varying degrees. Funding and the supply system affect availability of contraceptives at sites. The lack of specific methods affects the programs' ability to offer effective family planning services.}

Lack of availability of contraceptives is a general problem, although to differing degrees. In the Dominican Republic, stock outs were considered a problem. According to respondents, the $\mathrm{MOH}$ relies on funding from donor agencies. For instance, in the 3 regions of the country that are supported by UNFPA, "they have family planning methods both in variety and quantity." For the remaining 5 regions, stock outs sometimes occur. An interviewee explained that USAID had previously supported family planning, but then family planning seemed to receive less attention than HIV/AIDS. Now, USAID is supporting family planning again. At one out of two hospitals visited in the capital, providers talked about how stock outs have been a problem and continue to be. In the family planning program, they only had pills available. (The PMTCT program has condoms available since the offering of free condoms is considered part of the program.) The hospital depends on the MOH to supply them with contraceptives. 
In Uganda, national stakeholders were in consensus about stock outs being a common and major problem. One respondent talked about breaks in the supply chain from the national to the lower level health units. Another respondent explained that "the logistic management system has been changed from a push system to a pull system. It includes all $\mathrm{MCH}$ drugs and contraceptives. The health facilities need more training and support to use the new ordering forms and to order in a timely fashion." (Another program manager talked about this same difficulty of adapting to a new system in Tanzania. Health facilities used to get supplies sent to them, but now have to forecast and request commodities.) At the 3 sites visited, however, providers talked generally about having contraceptive methods with a few stock outs here and there. A program manager in Uganda put in context that the sites visited would likely have more commodities than health facilities further away. Also, it is the lower level health facilities that seem to have greater commodity problems.

In Kenya, national stakeholders did not talk about an overall problem of stock outs, but rather identified a couple of methods that were not available at the time of the interview. These included Norplant and Depo Provera. (The lack of Depo Provera is significant since providers identified it as the most popular method.) At the 2 sites visited in Nairobi, they were currently adequately stocked except for Norplant according to one respondent. Providers at one health facility specified that they receive contraceptive supplies from a government depot 10 minutes away from the clinic. This implies that the proximity to a government depot was a factor contributing to having necessary supplies.

In Thailand, Norplant was cited as being unavailable. One stakeholder spoke about the relationship between unavailability of a particular method and women's use of that method as well as its effects on the PMTCT program. "We have had stock outs with injectables, resulting in the prevalence of women using this falling substantially. Presently, we are having problems with Norplant, as our supplies are limited. I believe that as a result, the number of HIV-positive women becoming pregnant has been increasing."

International program managers echoed this theme of how the lack of family planning supplies adversely affects services. For instance, one individual stated that an ongoing challenge within family planning is commodities. "As Deliver [a technical support program for contraceptive logistics] says, no product, no program." Another individual described the dynamics of how the lack of specific methods can influence behavior. For example, in terms of surgical methods, even when they are available, women are told to come back another day. Then it is unknown whether women come back. She has also observed that while male condoms tend to be available, female condoms can be for demonstration only, and are not offered. Repeatedly, interviewees indicated that from their observations, Catholic institutions do not carry condoms. These examples illustrate how unavailability of methods as well as stock outs may be barriers to women's use of contraception. 


\section{Box 1}

Sites run by faith-based organizations provide limited family planning counseling and little or no family planning services.

Program managers at both the national and international levels brought up how faith based organizations can have a different orientation with respect to family planning. (These responses came up spontaneously as part of answering questions about service organization. There was no specific question about faith based organizations.) For instance, according to one respondent, faith based organizations do not offer family planning services or ask that you come as a couple. Catholic institutions have great counseling on natural methods but do not go beyond that. It is difficult for women to ask nuns (who are the health providers) about other methods. In theory, they are supposed to be able to provide referrals. Another interviewee described how Catholic facilities talk about rhythm methods, and that even condom use among discordant couples are not offered. She spoke about how there is likely to be variation among Catholic run facilities. This variation may exist by sites as well as within sites based on comments from another interviewee. She talked about how the more open-minded providers will let clients know where they can get them. This is at the discretion of the provider, and is not likely to be institutionalized. These observations touch on potential barriers to women accessing family planning methods.

There is also a distinction made between Catholic and Protestant groups. The former has been identified as narrowly offering natural methods of family planning. For instance, an individual associated with a Protestant group articulated that Catholic institutions do not have condoms available nor do they appreciate sister missions such as themselves who try to promote condoms for both HIV prevention and a family planning method. For this Protestant group, condoms are part of PMTCT supplies, and are thus available for free at all of the sites. Yet another Protestant group mentioned its own limitations with respect to condoms. "We discuss all the methods of family planning and then we emphasize the favorable methods for HIV-positive mothers like the oral contraceptives, condoms - but we emphasize condoms only for family planning not for HIV prevention because our mission health facilities insist on abstinence as a prevention method."

Limited family planning counseling and/or services offered at faith-based organizations is significant since faith-based organizations are important implementers of PMTCT services. In the UN-sponsored evaluation, sites in Rwanda supported by Catholic organizations, emerged as some of the most effective in offering PMTCT services such as counseling and testing, short course ARVs, and infant feeding counseling. However, the services at these sites excluded comprehensive family planning counseling and method provision.

\section{Family planning services are offered for free or for a fee depending on how services are organized.}

When asked if patients pay for contraceptives, there was a range of responses. In Uganda, all the providers interviewed indicated that contraceptives are free. In Kenya, 
there is not a charge per se for contraceptives, but there is a minimal charge for a general service patients receive which includes a physical examination, counseling and contraceptives. In Thailand, there is a 30 baht universal health coverage system whereby if people go to the hospital in their district they do not have to pay beyond $30 \mathrm{baht}$, which is less than 1 USD. Thai providers indicated that if patients have a health insurance card (under the coverage system) they did not have to pay. In the Dominican Republic, contraceptives are free to HIV positive women under the program, but HIV negative women pay a small amount for methods. Finally, in Cameroon, program managers indicated that women are currently paying for contraceptives so the PMTCT program is applying for donor funds to cover this.

In a number of PMTCT programs and government health services, condoms in particular, are provided for free. In Cameroon and Dominican Republic, condoms are specifically listed as part of the PMTCT program inventory, and are thus available for free. Moreover, in Thailand, South Africa, and Uganda as examples, interviewees reported that condoms are given for free at government health facilities regardless of whether PMTCT programs are in place.

\section{COMMUNITY AND INDIVIDUAL OPINIONS ABOUT HIV-POSITIVE WOMEN AND CHILDBEARING}

\section{Community norms about HIV-positive women bearing children range widely while women at PMTCT sites generally believe HIV infected women should not have children.}

Attitudes towards HIV-positive women bearing children vary depending on the extent of openness about HIV/AIDS, fertility norms, and knowledge of PMTCT programs. Providers in high HIV prevalence areas discussed how communities are in denial about HIV/AIDS. HIV/AIDS is not openly discussed and it is unlikely there would be public opinion expressed about HIV-positive women becoming pregnant. In these communities, providers believed that the decision to get pregnant is something discussed at an individual level among the infected and affected. One provider said that in her area some communities criticize HIV-positive women who get pregnant. They assume she knew her sero-status though generally this is only something that a woman discovers during ANC after she is pregnant. With the introduction of the PMTCT program at the hospital, a few people in the community have learned about the program. This seems to have changed their feelings towards HIV-positive women bearing children because they know that there is a chance that the child will survive to "carry" the name of his/her parents. In these communities, not having a child is considered worse than AIDS.

During community focus group discussions in Zambia, some participants expressed pronatalist views in light of PMTCT programs. They noted that PMTCT programs offer hope to HIV-positive couples who want to have children and that such programs would and should help parents have uninfected children. 
"If a woman is HIV-positive and looks and feels healthy, then she can try having a baby."

"Although family planning counseling is a good strategy of preventing mother-to-child transmission, the problem is if people were to use condoms all the time, there would be no children in the compound. So the drug [antiretrovirals for PMTCT] is giving hope to us HIV-positive individuals about the possibility of having healthy children. We must tell people not to use condoms but to go and access PMTCT in order for them to have children."

However, many individuals have witnessed children in their communities infected with HIV who fail to thrive and die or are orphaned. Women who have received services at antenatal clinics with PMTCT programs were generally opposed to HIV infected people bearing children. Many were outright against HIV infected individuals having sex. In Lusaka, when asked if HIV infected people should be sexually active, 98 percent of both HIV-positive and -negative women interviewed 9 months postpartum responded that they should not be. A high proportion of HIV-positive and -negative women gave the same response at one site in Kenya (Homa Bay) while at the second site (Karatina) there was a divergence of opinion between HIV-positive and -negative respondents with only 44 percent of HIV-positive women compared to 63 percent of HIV-negative women responding HIV-positive people should not be sexually active. (The Kenya interviews were conducted at 12 months postpartum).

Over half of HIV-positive and -negative women in Lusaka stated that refraining from sexual activity would prevent the infection of others, while about a third mentioned the need to prevent re-infection. Roughly 10 percent expressed that not being sexually active would prolong life. Women in Karatina agreed with 87 percent saying people living with HIV should avoid sex to avoid infecting others and most of the rest saying to avoid reinfection. Women in Homa Bay thought the main reasons HIV infected people should not have sex was to avoid re-infection (56 percent) and secondly to avoid infecting others (36 percent).

When asked about HIV infected people bearing children, there was strong agreement by both HIV-positive and -negative women in the Horizons study in Kenya that HIVpositive people should not bear children, with more than 85 percent of women expressing this view. The overwhelming reason provided was that the children will be infected, then suffer and die. The next most commonly given reason was concern for the health of the mother. More rarely cited was the prospect of orphanhood as a reason for avoiding pregnancy. The principal reasons given for supporting HIV infected people to have children, among the minority that held that view, were that it is natural and/or important to have children and children won't necessarily have HIV.

Individual decisions demonstrate the difficult balancing between achieving a family size compatible with individual preference and cultural norms, and having healthy children. 
When HIV-positive women (and sometimes their partners) have to confront the personal decision about whether to have another child or not, providers report that most women want one or two children, or at least one boy, or at least one boy and a girl, or at least one child with a second husband, depending on the setting. Thus women who learn their status after having given birth two or more times may be less likely to want more children than women who learn their status in a first or second pregnancy. One provider in India explained "a lot of [PMTCT clients] say that if there are two children, at least after their parents' death the siblings will be together and not alone." The reasons for having a small number of children include wanting to leave offspring to carry on the name, to cement the marriage, and to avoid attracting attention and community stigma by going against community norms about childbearing.

For many of those who know about it, the PMTCT program gives hope to have an HIVfree baby. According to one provider in Uganda, "Previously they used to fear producing because they knew it would lower their immunity and the child may be infected. But now with PMTCT awareness, that fear is gone. They now know there is a way of preventing mother-to-child transmission." Similarly a provider in India reported "With PMTCT services available, women are coming back for a second delivery even after the first child was born positive - they hope to have an HIV free baby."

Some reasons were cited why HIV-positive women should avoid pregnancy including: the fear that pregnancy further reduces the immunity of HIV infected women, learning one's HIV status is stressful and going through another pregnancy would exacerbate that stress, and HIV-positive women have doubts about whether the PMTCT intervention will be effective in preventing infection in the children.

The quality or content of counseling may influence women's decision. One provider told us "Most pregnant mothers who come to the clinic and get to know they are HIV-positive opt not to have another child after receiving adequate counseling..."

\section{DEMAND FOR FAMILY PLANNING AMONG HIV-POSITIVE WOMEN}

\section{Fears about contraception and HIV-positive women's health}

Particularly in the low contraceptive prevalence areas in East Africa where we conducted interviews, there continues to be strong fears about the impact of contraceptive methods on women's health, regardless of HIV status. Litanies of fears, as reported by this provider were not uncommon: "Regarding the pill, they [women] say that it accumulates in one place in your abdomen and causes fibroids. Some women also say that Depo causes them to bleed and lose libido. Others say that Norplant goes up to the heart and leads to death while others claim that IUD causes cancer." Providers also reported fears about contraceptives causing infertility or abnormalities in future children and "some [women] also believe that pills and the injectables contain the HIV virus." Some HIV infected women are concerned that contraceptive use will make their illness worse. 


\section{Condoms viewed favorably by HIV-positive women}

Interestingly, condoms emerge as being positively perceived by HIV-positive women, in part because they offer dual protection against re-infection and STIs as well as an unwanted pregnancy, but also because they are seen as safe-as well as cheap and readily available. Moreover, the PMTCT sites promote them for HIV-positive women. In all secular sites visited in Uganda, Kenya, India, Thailand, and the Dominican Republic, providers and managers indicated that condoms are offered at the site, and are actively promoted for dual protection against HIV/STIs and unwanted pregnancy or for HIV/STI prevention in conjunction with a highly effective contraception method such as sterilization. Indeed, individuals at the site, national, and international levels brought up and underscored how important dual protection was for HIV-positive women in their program.

In some settings (particularly in Uganda and Kenya), getting the partner to accept condom use is a large, and at times insurmountable, challenge. It is easier to introduce condoms when a woman has disclosed her status and then she (and sometimes her partner) are motivated to avoid infection or re-infection. According to one provider, "Others [HIV-positive women] are on Depo but later they withdraw after they have disclosed their HIV status to their husband and opt for condoms." Another PMTCT provider told us "that those who have tested and are living together use condoms. We have a saying, 'let your virus be yours and mine be mine'." Yet women are often reluctant to disclose their HIV status as fear their husband's reaction, particularly being "chased away". According to one Ugandan provider, "The ones who come with their husbands when they already know their status are fine but those who test alone have a problem. When you ask those who've tested positive whether they are going to tell the husband, the answer is NO."

One site in India reported a large number, almost 40, discordant couples (all the husbands are negative, know the status of their wives, and have come in for counseling session). The women are very worried about infecting their husband and condom use is very high. In Thailand, providers noted that there was little interest in dual protection as most women are infected by their husbands and thus did not see the need for a barrier method.

In the Horizons study in Lusaka, 9 month postnatal clients were asked which of the following family planning methods are good for HIV-negative women (see Table 2). The responses were very similar between HIV-positive and negative women, with no statistical difference in attitudes about any specific method. Moreover, the majority of women responded that all of the family planning methods were good for HIV-negative women. Postnatal clients were also asked about which family planning methods are good for HIV-positive women. Women were twice as likely to say condom than any other method. 
Table 2 Postnatal clients' views on good family planning methods for HIV-positive and -negative women

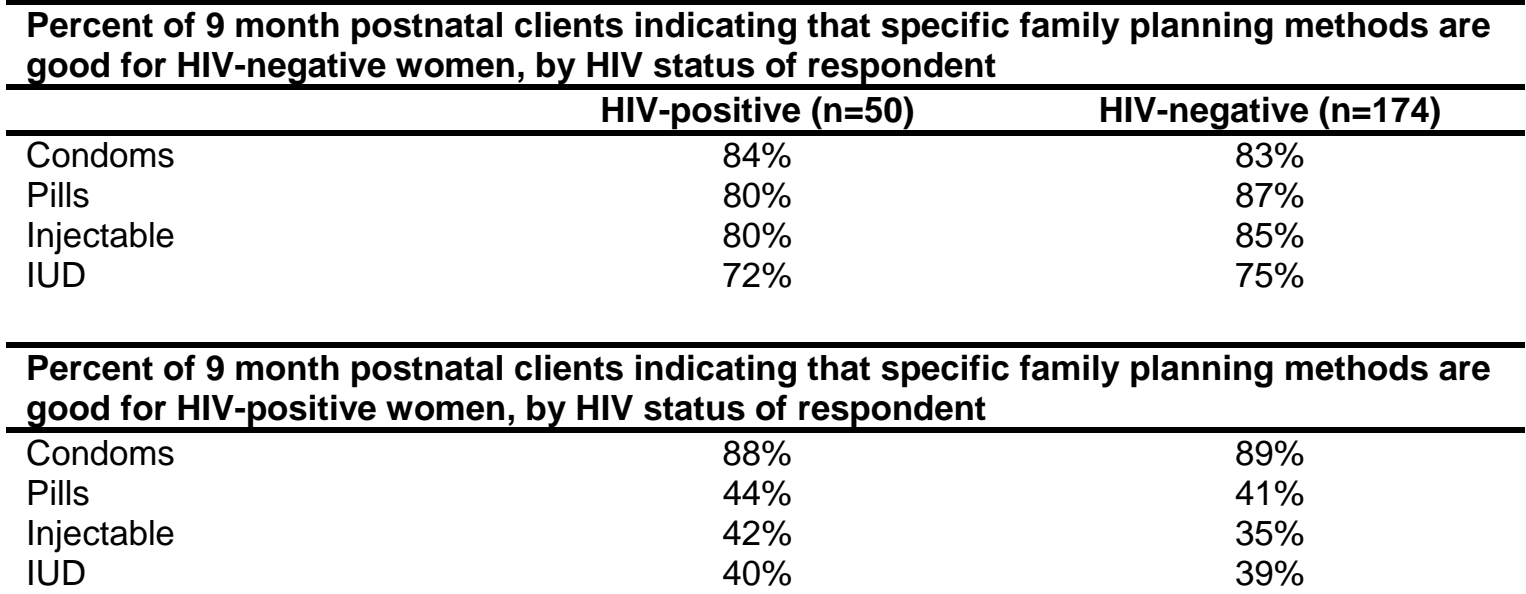

\section{USE OF FAMILY PLANNING AMONG PMTCT CLIENTS}

When family planning is not well integrated into PMTCT settings, HIV-positive and HIV-negative women are just as likely to use family planning methods, with the exception of condoms.

In low contraceptive prevalence, low resource and high HIV prevalence settings such as Kenya and Uganda, family planning services are generally parallel rather than integrated into PMTCT services. In these settings, we found that the use of family planning among HIV-positive women is quite similar to that of HIV-negative women. At six months postpartum, one-third of women in the cohort who received antenatal care at the PMTCT site in Lusaka and just less than one-quarter of clients at the PMTCT site at Homa Bay were using a modern method of family planning (see Table 3). Family planning prevalence in Karatina was considerably higher, with more than three-quarters of clients adopting a modern method of family planning. In Lusaka, HIV-positive and -negative women reported similar rates of specific contraceptive methods, with the exception of condoms. These rates are broadly comparable to the contraceptive prevalence figures reported for the respective districts in recent DHS studies, suggesting that the uptake of family planning by women at these sites reflects the overall level of family planning effort rather than the addition of PMTCT services. Similar levels of contraceptive use by HIV-positive and -negative women suggest that such factors as local norms about fertility control and the acceptability of contraception play a greater role than HIV status in determining contraceptive use. 
Table 3 Percent of use and non-use of family planning of PMTCT clients at 6 months postpartum, by HIV status

\begin{tabular}{|c|c|c|c|c|c|c|c|c|}
\hline & Pill & Injectable & Long-term & Condom & $\begin{array}{c}\text { Total } \\
\text { modern } \\
\text { method }^{\mathrm{a}}\end{array}$ & $\begin{array}{l}\text { Natural } \\
\text { family } \\
\text { planning }\end{array}$ & $\begin{array}{c}\text { None, } \\
\text { no partner }\end{array}$ & $\begin{array}{l}\text { None, } \\
\text { regular } \\
\text { partner }\end{array}$ \\
\hline \multicolumn{9}{|l|}{$\begin{array}{l}\text { Lusaka, } \\
\text { Zambia }\end{array}$} \\
\hline $\begin{array}{l}\text { HIV+ } \\
(n=69)\end{array}$ & 7 & 4 & 0 & $23^{b}$ & 32 & 3 & 15 & 39 \\
\hline $\begin{array}{l}\text { HIV- } \\
(n=220)\end{array}$ & 14 & 10 & 1 & $9^{b}$ & 33 & 3 & 7 & 44 \\
\hline \multicolumn{9}{|l|}{$\begin{array}{l}\text { Homa Bay, } \\
\text { Kenya }\end{array}$} \\
\hline $\begin{array}{l}\text { HIV+ } \\
(n=62)\end{array}$ & 2 & 16 & 2 & 0 & 19 & 3 & 11 & 65 \\
\hline $\begin{array}{l}\text { HIV- } \\
(n=163)\end{array}$ & 4 & 12 & 4 & 1 & 21 & 1 & 5 & 69 \\
\hline \multicolumn{9}{|l|}{$\begin{array}{l}\text { Karatina, } \\
\text { Kenya }\end{array}$} \\
\hline $\begin{array}{l}\mathrm{HIV}_{+} \\
(\mathrm{n}=37)\end{array}$ & 24 & 49 & 3 & $11^{\mathrm{b}}$ & 87 & 0 & 11 & 3 \\
\hline $\begin{array}{l}\text { HIV- } \\
(n=237)\end{array}$ & 17 & 47 & 11 & $1^{b}$ & 77 & 5 & 9 & 8 \\
\hline
\end{tabular}

Two-thirds of women interviewed in Homa Bay and more than one-third in Lusaka reported that they were not using any family planning method, although they did have a regular sexual partner. The lack of family planning use with a regular partner suggests potential future pregnancies among both HIV-positive and -negative women.

In Lusaka, nearly a quarter of HIV-positive women reported condom use at six months postpartum, which is more than double the use of condoms by HIV-negative women. The 9 percent of HIV-negative women who reported condom use is consistent with the DHS for Lusaka, while HIV-positive women reported much higher use (23 percent) than the general community practice. HIV-positive and -negative women in Karatina also reported similar rates of specific contraceptive methods with the exception of condoms. The low one percent of HIV-negative women who reported condom use is also consistent with the DHS for the central province in Kenya. Meanwhile, HIV-positive women reported significantly higher use of condoms (11 percent). In Homa Bay, condoms were barely used by either HIV-positive or -negative women.

\section{HIV-positive women's use of condoms is much greater than HIV-negative women's use in 2 sites in Kenya and Zambia}

Women were asked at 12 months postpartum in Kenya and 9 months postpartum in Zambia if they never, rarely, sometimes, often or always used condoms with their spouse or regular partner. 
In Lusaka, there was a noticeable difference in condom use with spouse/regular partner between HIV-positive and -negative women at 9 months postpartum (see Table 4). More than one-third (36 percent) of HIV-positive women reported condom use with spouse/regular partner as 'often' or 'always' in contrast to just 10 percent of HIVnegative women. More than one-third of HIV-positive women (36 percent), compared with 55 percent of HIV-negative women, reported no use whatsoever.

Similar to Lusaka, in Karatina, there was a dramatic difference in condom use with spouse/regular partner based on HIV status at 12 months postpartum. Two-fifths of HIVpositive women reported regular (often or always) condom use in contrast to less than 2 percent of their HIV-negative counterparts. Forty percent of HIV-positive individuals reported that they never used condoms while 87 percent of HIV-negative women reported complete lack of use.

These data suggest that at these two sites, a significant minority of HIV-positive women who are still connected with the MCH system (i.e., the subset of our original study cohort who returned for $\mathrm{MCH}$ visits) have been successful in regularly using condoms within their relationships. This level of condom use is much higher than the general community practice. At both sites, these percentages of condom use are increases from the reports of HIV-positive women at 6 months postpartum. These findings suggest that, with time, clients may have heard more messages about the importance of condom use and/or gotten support from $\mathrm{MCH}$ providers and that those who remain in the $\mathrm{MCH}$ system may be more likely to practice positive behavior.

Table 4 Percent of condom use with partner/spouse 9-12 months postpartum, by HIV status

\begin{tabular}{lcc}
\hline & Never & Often or Always \\
\hline Lusaka (9 months) & $36 \%$ & $36 \%$ \\
HIV+ $(n=50)$ & $55 \%$ & $10 \%$ \\
HIV- $(n=174)$ & & \\
Karatina (12 months) & $40 \%$ & $40 \%$ \\
HIV + $(n=25)$ & $87 \%$ & $1.5 \%$ \\
HIV - $(n=195)$ & & \\
Homa Bay (12 months) & $82 \%$ & $2.6 \%$ \\
HIV+ $(n=39)$ & $81 \%$ & $2.5 \%$ \\
HIV - $(n=59)$ & &
\end{tabular}

Similar results are obtained from a question on whether respondents used a condom the last time they had sex with their spouse or regular partner. When women in Lusaka were asked about condom use the last time they had sex, at 9 months postpartum, nearly half (46 percent) of HIV-positive women indicated condom use with last sex with partner while over a fifth (22 percent) of HIV-negative women indicated condom use.

In Homa Bay and Karatina, this question of whether a condom was used at last sex with partner was asked only to those who responded that they used condoms (ranging from rarely to always). Consequently, the number of respondents is small since they are a subgroup of the larger population of interviewees. When asked at a year after delivery, in 
Homa Bay 3 out of 6 HIV-positive women reported condom use at last sex with partner while 5 out of 12 HIV-negative women reported such use. In Karatina, 9 out of 16 HIVpositive women reported condom use at last sex with partner in contrast to 7 out of 25 HIV-negative women.

In high contraceptive prevalence and relatively high resource settings where HIVpositive women receive specific counseling about sterilization, many women have undergone sterilization.

In the Dominican Republic, all HIV-positive women are offered elective caesarean sections for delivery and sterilization-either in conjunction with the caesarean or a tubal ligation following a vaginal delivery. One hospital in Santo Domingo reported that among the 14,000-15,000 annual deliveries in the hospital, 110-120 are HIV-positive women. 85 percent of these women elect to have a caesarean section and 99 percent have sterilization either at birth or 10 days post-partum. A PMTCT program manager at a second hospital in the city reported that condoms from the PMTCT program are used for HIV prevention because almost all of the HIV-positive women have undergone sterilization.

No data on sterilization rates by HIV status are available for the Dominican Republic. However, almost universal rates of sterilization among HIV-positive women are not incongruous with the overall high acceptance of sterilization in the country; more than one-quarter of women are sterilized before age 25 and more than two-thirds of women in union over the age of 35 have undergone sterilization (Achecar et al. 2003).

Thailand shares a broadly similar profile with the Dominican Republic. In a study of HIV-positive women (median age 26 years) from 37 hospital sites throughout the country, researchers found that the overall prevalence of sterilization at 6 weeks postpartum was $56 \%$, while $92 \%$ of women indicated they were using some form of contraception $(\mathrm{n}=1764)$. While sterilization is the second most common contraceptive method with a quarter of currently married women having been sterilized, sterilization is greater among HIV positive women when compared to their HIV negative counterparts (Lallemant et al. 2004).

Providers in India also reported that sterilization is the most common contraceptive method in the country and sterilization is the most popular method among HIV-positive women. Providers strongly recommend that women who opt for sterilization use condoms as well.

\section{INTEGRATION OF FAMILY PLANNING AND PMTCT SERVICES}

Availability of family planning services at PMTCT sites does not ensure integration of HIV and family planning messages. 
While it is important that family planning services are available for patients' use in PMTCT sites, this does not naturally translate into integration of HIV and family planning messages. During observations of family planning sessions at the six pilot PMTCT sites in Zambia, the sessions were generally of good quality, with most providers exploring the client's reproductive health goals and explaining the advantages and disadvantages of various methods of family planning, as well as giving correct instruction in the family planning method selected or in use. However, there was little integration of HIV issues into family planning counseling. Among the 48 sessions observed, family planning providers mentioned HIV transmission in only 12 sessions, HIV testing in nine sessions, and PMTCT in eight sessions. That the risk behaviors for HIV and pregnancy are the same was mentioned in 10 out of 48 sessions. Finally, providers brought up using condoms for dual protection against HIV and pregnancy in only 16 of 48 sessions observed.

There was also little integration of HIV issues in observations of family planning sessions in the two sites in Kenya despite the introduction of PMTCT. In Homa Bay, dual protection was discussed in 14 percent, 25 percent, and 10 percent of sessions for the three rounds of observation. In Karatina, dual protection was hardly mentioned, with less than 3 percent for all rounds. Providers improved significantly in informing clients that the risk behaviors for HIV and pregnancy are the same, yet by the third round this was brought up in less than half of the sessions in Homa Bay (43 percent), and just 16 percent in Karatina.

The low frequency of integrating HIV issues and exploring the potentially different needs of HIV-positive and negative women may be one factor contributing to the lack of difference in family planning practice relative to HIV status in these settings.

Family planning is usually provided in PMTCT training, but is not considered a priority, and is thus allotted minimal time. The content of family planning training varies among countries in part based on what methods are offered.

One reason for the lack of integration of family planning and PMTCT is the low priority given to this topic in PMTCT training. Sometimes the topic is excluded from the PMTCT training because it is assumed that $\mathrm{MCH}$ providers have been trained previously in family planning. More often, some family planning training is provided during PMTCT training but it is not a priority. As one respondent indicated, "family planning is not emphasized, it is taught more as a by-the-way subject in most trainings." In order to be included in the training, family planning needs to be part of the training curriculum. In the countries where family planning is included in the training manuals, stakeholders often mentioned that the information did not go into detail. In Uganda, a family planning module has recently been added into the National PMTCT Orientation of Health Staff manual and the PMTCT Counselor Training manual.

The duration of the family planning training constitutes a small part of the PMTCT training. For instance, while respondents in India did not specify in terms of hours how long the family planning training lasted, they indicated that the time for family planning 
was short, and not adequate. Meanwhile, family planning training in the Dominican Republic is about 2 hours for counselors according to one respondent. And in Thailand, one section that lasts 15 minutes is directly given for family planning training although family planning materials are integrated in other sessions throughout the week. In Cameroon, during a week of PMTCT training, family planning training takes 2 or 3 hours. Finally in Kenya, most national stakeholders are implementing a 2 week training for PMTCT, of which family planning takes 30 minutes to a few hours.

In part depending on the methods offered for family planning, training is considered as part of antenatal and/or postpartum care. For instance, in India, family planning is mentioned under antenatal care where subject items include providing choice of medical termination of pregnancy or continuation of pregnancy for HIV-positive women. Family planning is also mentioned as part of antenatal care counseling/education in the Dominican Republic since HIV-positive women are offered caesarean as well as sterilization. Meanwhile in Thailand, family planning training is given as part of postpartum care.

The family planning content with PMTCT training also varies among countries. In Kenya, the topics covered include the types of family planning methods, the need to do family planning, the special needs of HIV-positive women, and emphasis on dual methods. In India, the emphasis is on offering information and advice on barrier methods/condoms for STD/HIV prevention, unintended pregnancy and MTP for HIVpositive women who are pregnant and within legally permissible limit (less than 20 weeks of gestation).

\section{Communications programs for family planning and PMTCT are vertical programs. Both promote the well being of the family but messages are not integrated.}

Another reason for the lack of integration of family planning and PMTCT information and services is that family planning and PMTCT communications programs are vertical in both communities and clinics. Family planning messages raise awareness about and encourage women and their families to use contraception for their health and the health of their family. PMTCT communications generally have a central message about how the services offered by the program can help couples have an uninfected child. For example, the logo for the national communications program in Uganda reads as follows: "HIVpositive parents, HIV-negative baby, it is possible". Similarly, a poster in a large Kenya PMTCT program reads "An HIV-positive pregnant women can transmit the HIV virus to her child in the following ways 1) before birth 2) during birth and 3) during breastfeeding. A child has a right to be born / live HIV-negative."

In order to reduce vertical transmission for the specific current pregnancy, PMTCT programs discuss the associated activities to reduce transmission. As such, some PMTCT programs start with basic HIV/AIDS education and discuss different modes of transmission. Many programs provide information about mother to child transmission and promote the benefits of the PMTCT program. They encourage ANC attendance and delivery at a health facility. They discuss the availability and importance of HIV testing 
during ANC, and encourage women to test. They explain that if a woman tests positive, HIV-positive women will receive treatment at the health facility such as short course ARVs and safer infant feeding recommendations. One program manager's response is a summary of what so many others explained in detail - the "main messages are all around prong 3: HIV test, ARVs, and infant feeding, nothing else."

Mothers 2 Mothers $2 \mathrm{Be}$, a peer support program for HIV-positive women in Cape Town, South Africa, is an exception in that family planning is one of three main messages communicated to their clients (short course ARV therapy and infant feeding are the other two). While counseling mothers, issues related to disclosure of status in relationships are brought up. These discussions are then the entry point to talk about sexual practices and family planning practices after birth. These HIV-positive women are encouraged to select and follow through on a family planning method.

Despite the fact that family planning is not usually a key message within PMTCT communications as a whole, there appears to be increased opportunities to discuss family planning among older programs (e.g., 2 or more years) according to one respondent who is familiar with programs in several sub-Saharan African countries. She is starting to see discussions about family planning and how that contributes to PMTCT among implementers at different level. At the site level, she has observed that opportunities for communications in general are growing such as ANC group talks, HIV-positive support groups, and that family planning is being talked about in these group settings. She attributes this change to more consciousness among implementers about family planning since few women receive all PMTCT services, and thus other things need to be tried. Program managers working at the national level in the Dominican Republic, India, and Namibia pointed out that family planning would be part of communications messages to go out to communities, suggesting that family planning may be increasingly recognized as a method to prevent MTCT.

\section{At the national level, family planning and PMTCT are separate programs, often with separate funding.}

At the national level, family planning and PMTCT generally tend to be under two different departments. The former falls with the reproductive health/MCH unit, while the latter falls within HIV/AIDS. In India for example, activities related to family planning are under the aegis of Department of Family Welfare, while HIV/AIDS is under Department of Health. And in the Dominican Republic, the PMTCT program is under the management of a department that focuses on HIV/STI, and not reproductive health. This means that individuals are not usually working alongside one another day to day.

Moreover, often these departments receive distinct funding flows to meet either reproductive health objectives or HIV objectives. Interviewees talked about how funding for HIV programs, which focus on HIV prevention - including in infants - sometimes do not permit the money to be used for broader reproductive health programming, even if this would contribute to averted infections. As just one example, individuals working at a large PMTCT program talked about not having funding to offer family planning 
commodities other than condoms, and thus women are paying for them. (They are in the process of applying for funding for free family planning methods for HIV-positive women.) However, in the Dominican Republic, FHI's CONECTA project has received both HIV/AIDS and RH funds from USAID. Thus CONECTA is uniquely positioned with the mandate to increase family planning and to increase PMTCT out of the same project. As another example in the Dominican Republic, funding from UNFPA enables health facilities in 3 out of the 8 regions in the country to be well supplied with contraceptives.

Yet there are examples of increased communication and coordination. In Kenya, one national stakeholder explained that "At the beginning when we formed the PMTCT technical working group, the focus was not broad. It started from ANC activities and stopped after delivery. PMTCT was thought of as an Obstetrics and Gynecology problem, so the focus was ANC not family planning. Currently we have representatives from the Division of Reproductive Health on board." In Uganda as well, the RH division of the MOH is represented on the MTCT coordinating body. A national stakeholder describes how PMTCT and MCH are intertwined. "When you are implementing PMTCT, this is being implemented within a wider context of MCH. It's not necessarily PMTCT people doing family planning, but reproductive health people. It then appears that there is need for coordination between reproductive health and the PMTCT unit."

\section{Pilot project in Uganda shows that HIV issues can be successfully integrated into family planning sessions.}

Results from a Horizons study in Uganda demonstrate that it is possible to increase integration of HIV issues into family planning sessions. The study tested an approach to addressing constraints to integrated reproductive health (family planning and STI management) and HIV services (voluntary counseling and testing) by providing training in integration and HIV counseling skills to providers, charging supervisors with monitoring the integration of services, the development of IEC materials that promoted integrated services, and a special clinical assessment tool to determine the needs of the client beyond the service they primarily sought. In this intervention, family planning providers were trained to bring up HIV issues so that the specific needs of HIV-positive women, HIV-negative women, and those of unknown status could be addressed. Providers could then refer clients to such HIV services as VCT. Researchers observed more than 60 sessions.

From the baseline observations conducted in 2000 to the follow-up observations in 2001, there was a dramatic increase in the percentage of family planning sessions where HIV needs were assessed, HIV risk was discussed, and dual protection was proposed (see Figure 2). Indeed, the percentage of sessions in which HIV needs were assessed more than doubled, as did the percentage of sessions in which the provider proposed dual protection. 
Figure 2 Percent of observed family planning sessions in Uganda in which HIV issues are addressed before and after integration intervention

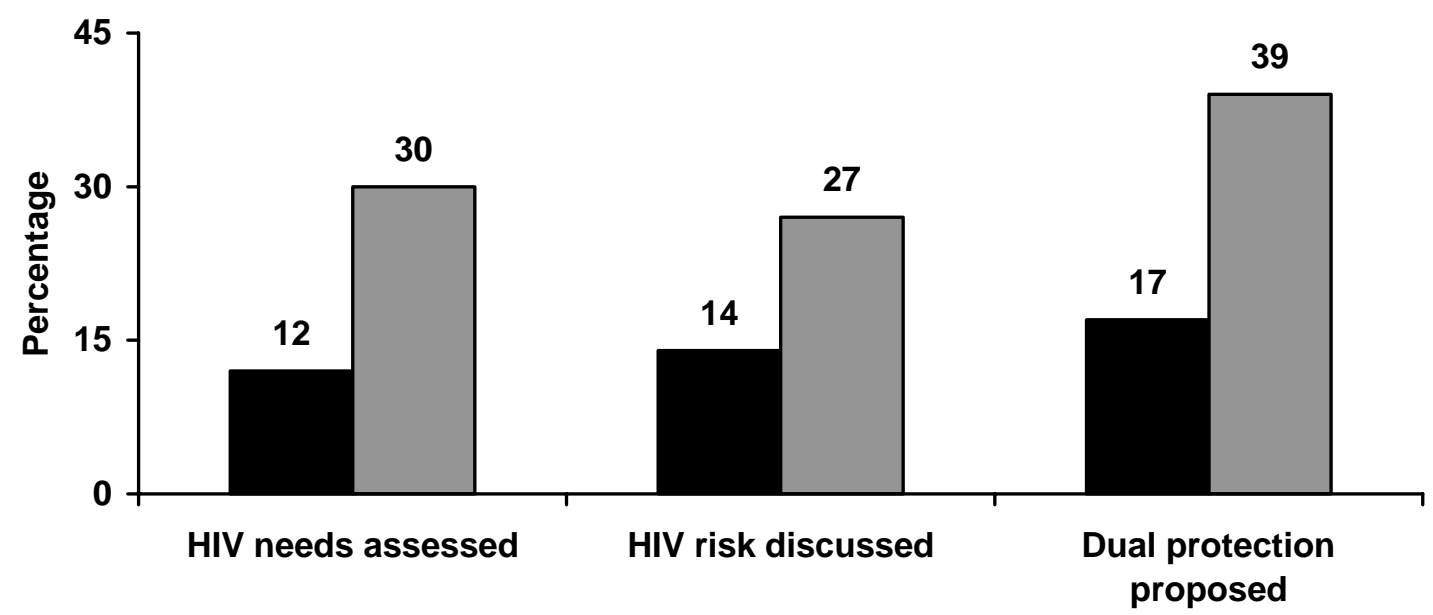

Baseline $\square$ Follow-up

\section{CHALLENGES TO PRIORITIZING FAMILY PLANNING AS A PMTCT SERVICE}

\section{Within the four strategies of the UN Framework to reduce vertical transmission, implementers focus on the third strategy.}

While PMTCT stakeholders support the $4 \mathrm{UN}$ strategies to reduce vertical transmission, many have prioritized implementation of the third strategy. ${ }^{5}$ One implementer in Cameroon stated "with these types of programs, you have to start somewhere so emphasis has been on prong 3." Others corroborated that the third strategy has been the main focus. While one international program manager articulated that the 4 prongs could not all be the responsibility of one group, another spoke about how most programs begin with the third, and her organization's guidelines support the transition from the third prong to the second and fourth. Respondents from two countries with programs that have been up and running for more than a couple of years indicated that the program was now at the point where family planning can be incorporated. These comments suggest that, for most programs, the second cornerstone of PMTCT is not an immediate priority, but rather a strategy that is given more attention once the program has matured.

\footnotetext{
${ }^{5}$ The 4 UN strategies to prevent mother to child transmission are as follows: 1) primary prevention of HIV infection in women 2) prevention of unintended pregnancy among HIV-positive women 3) reducing transmission from HIV infected pregnant and lactating women to their children, and 4) care and support of women, infants, and families infected and affected by HIV/AIDS.
} 
There is a lack of consensus about how to implement the second strategy of the UN Framework. One perspective recommends health providers to actively encourage family planning for HIV-positive women. Another perspective recommends health providers to support women's fertility desires, whatever they may be.

PMTCT stakeholders widely endorse the 4 strategies in the UN framework, including the second cornerstone, which is preventing unintended pregnancy among HIV-positive women. Yet when this strategy is discussed, there is a tension between prioritizing public health and reproductive rights. While there is some shared ground, there appears to be two competing perspectives. The first is a public health approach which recommends that HIV-positive women avoid future pregnancies in concern for the health of the woman as well as the well-being of her already born infant and other children. The second approach is embedded in a reproductive rights framework, in which women are supported in achieving sexual health regardless of their HIV status.

Interviews with stakeholders at site, national, and international levels revealed that although the policy is not clearly delineated, there are individuals who appear to be taking a public health approach. These individuals are actively encouraging family planning for HIV-positive women. Without any asking or prompting on the part of interviewers, stakeholders in different regions made similar comments along the lines of how family planning is an important theme because we have seen PMTCT clients in their second pregnancy. This implies that while the pregnancy in which clients make their first contact with the program may be viewed as unavoidable, a subsequent pregnancy should not have taken place, and that the program failed by not preventing this pregnancy.

One international program manager remarked that perhaps programs should take a more active approach regarding what is said to HIV-positive women. "When we say to prevent unwanted pregnancy, I don't know how many unwanted pregnancies there are. I wonder if it will play a crucial role in the number of averted infections. Should we be advising HIV-positive women not to be pregnant - this is a more active approach. Should we advise in general for HIV-positive women to not become pregnant - but leaving room so we are not forcing."

Providers in Kenya and Uganda echoed this sentiment:

"Most pregnant mothers who come to the clinic and get to know that they are HIV-positive opt not to have another child after receiving adequate counseling. A small number of women find it hard to imagine that they cannot have another child, but after counseling the couple, they come to terms with their state."

"When we are educating these mothers on PMTCT and especially those who are HIV-positive, we tell them about positive living and to avoid a pregnancy. The protocol says a mother is supposed to deliver the child and after that go for a family planning method. We counsel them about family planning and advise them on permanent method because we don't 
expect them to deliver again. We tell mothers family planning is one of the PMTCT methods. In PMTCT, family planning is also included because we need these mothers to live for more years, since they need to care for the child."

Rather than consciously directing HIV-positive women towards the use of permanent or temporary methods in order to avoid future pregnancies, the second approach centers around responding to women's reproductive health desires. This approach prioritizes the notion that all women have a right to bear children, regardless of HIV status. The role of the PMTCT program is to help women make informed choices and to provide information and services that minimize the probability of HIV transmission to their infants if they choose to become pregnant. Clients should be informed about the risk of vertical transmission, but within a balanced context. For example, this may include advising women of the percentages of possible vertical transmission, both without and with PMTCT interventions. This approach would then support whatever decision the woman makes about future pregnancies. One provider volunteered in Kenya, "We only inquire if they [clients] are interested in family planning and leave the clients to decide.'

UNFPA is providing support at a variety of levels to ensure HIV-positive women receive comprehensive sexual health services. Examples of such support include co-hosting with WHO the international meeting in spring 2004 to discuss integration of FP and PMTCT, and co-authoring with WHO modules on sexual and reproductive health for HIV infected women including use of all types of family planning methods. In 2004-2005, a UNFPA framework will be developed on sexual and reproductive health. This will help guide policy and programming to meet sexual and reproductive health needs of HIV-positive women, and family planning will be part of this.

\section{Male involvement is generally poor, and is important because women often need men's support to carry out family planning methods and benefit from other PMTCT services. Programs are now reaching out to men.}

Although there were no questions asked about male involvement as related to family planning and PMTCT, this was an issue raised by some of the interviewees. The overall sentiment was that male support is lacking and is needed in major part because male partners/husbands influence women's decisions. PMTCT interventions including family planning take place in antenatal care, a highly female environment in most settings. One program manager expressed that 'male involvement is critical but men don't come to ANC'. A provider in Uganda went on to say:

"One of the major challenges as I said is male involvement. I have a figure to show that only a very small percentage of men accompany their wives to either antenatal or to the family planning clinic. I think that has a lot of bearing on the decision making especially for the mother who has come for PTMCT or family planning. I would have been happier getting most of these men supporting their spouses in all ways through pregnancy and even when it comes to family planning." 
Other providers discussed the lack of male support, and specifically mentioned how it is difficult for women to use condoms because their male partners do not like them, and will not accept them. In Thailand, providers mentioned that one factor affecting whether a woman would choose to be sterilized is whether she has disclosed her HIV status to her partner.

Given men's significant roles, programs are making efforts to reach men. In the Dominican Republic where it is not uncommon to see men in the antenatal care setting, providers reported offering HIV testing and couples counseling. For male partners of women who have tested positive, providers discuss elective caesarean and sterilization with them. In India, the national program has adopted the phrase, Prevention of Parent to Child Transmission. This was done to remove what was perceived as blaming women as transmitters of infection as well as a means of encouraging male participation as a key strategy to reduce vertical transmission. This may be one way to ensure that men are not left out of the program and for health workers to realize the important role men play in the epidemic. Also, this is an opportunity to move towards a 'family' oriented approach to HIV/AIDS. In Uganda, the national communications program has embraced a family approach. Their logo has a pregnant woman with her male partner. One of their posters shows a woman smiling at her male partner who is holding their baby, with the accompanying text, "Richard and Mary are HIV positive, but their child is not." Also in Uganda, a PMTCT project at Mulago Hospital encourages male support by having a male access clinic in the evening. One focus of the program is to prevent unintended pregnancy.

\section{There is little monitoring and evaluation of family planning as a PMTCT service.}

The choice of indicators to monitor and evaluate programs can have substantial impact on program emphasis. Overall, donors are not requesting reporting about family planning use within PMTCT programs. One individual spoke about how their program reports on more indicators than what their major donor requires, and that the donor has not requested a family planning indicator. In a similar vein, another individual talked about how family planning did not seem to be a priority for their major donor, and there is a need for advocacy on reporting. Interviewees repeatedly responded that there were no indicators for family planning, and thus they did not know how many or what proportion of women are accessing family planning services. One individual commented that although there is no family planning indicator, it has come up doing discussions and people are thinking about it. The question is whether family planning should be a PMTCT indicator or a general MCH indicator.

There were a few examples given about monitoring family planning within PMTCT programs. For instance, one organization conducts baseline assessments of PMTCT programs. During these assessments, questions about family planning are asked. Yet because the emphasis is on prong 3 and there are many questions to ask in the baseline assessment, at times the family planning information is not fully filled in. Also, this organization has an indicator for family planning referral but the collection of referral 
data is not taking place. The respondent explained that it is part of the same challenge of tracking mothers and infants, especially post partum. Also, it is difficult because women have other places where they can get family planning services. In the Mothers 2 Mothers 2 Be program, each patient has a tick list, which includes family planning counseling/education. Yet, they do not have data for contraceptive use since that occurs in the medical facility, and M2M2B functions as a peer support program. Finally, in India, there were 45 indicators, including a couple of family planning indicators, when the PMTCT program was a pilot feasibility study. However, when the program was scaling up to become a national program, the indicators list was streamlined to $12-15$, and in that process, family planning information was removed.

\section{Human resources are not readily available in some settings to place greater emphasis on family planning.}

Interviewees working in sub-Saharan Africa indicated that human resources are considered to be a challenge. There is a shortage and/or the human resources on the ground are already overstretched. Interviewees made comments such as providers being very overstretched especially in sites where the same providers are caring for pregnant and post partum women as well as under $5 \mathrm{~s}$, and women are waiting a long time because providers do not have time as they have been given additional work. A couple of respondents reported that PMTCT programs have taken personnel from traditional programs such as family planning, and questioned what this would do to the quality of family planning provision.

However, in India almost all respondents at the national level felt that there were adequate human resources available to place greater emphasis on FP. These resources needed to be better utilized which required improved planning and coordination between the two departments of Health and Family Welfare at the Central/National level. More training was required for staff in Reproductive and Child Health programs on HIV/AIDS and family planning as related to HIV prevention. Meanwhile, at the state level, some individuals indicated that staff were overburdened.

In Brazil, the national program manager indicated that while there are deficiencies in human resources in some regions, this is not a significant problem since the Ministry of Health and the Brazilian Federation of Obstetrics and Gynecology have been training health professionals from different regions of the country in family planning.

Despite the identification of human resources as a problem in many settings, a few respondents indicated that there was potential for more emphasis on family planning for providers and that family planning is an important service that needs to be carried out well.

\section{Advocacy and leadership reinforce prioritization of family planning}

A positive element contributing to increased attention to integration of family planning and PMTCT is the role of national stakeholders. Most national stakeholders responded 
affirmatively when asked if the MTCT coordinating body or individuals in leadership positions could bring anything to bear such as advocacy/leadership to reinforce family planning as a method to PMTCT. Examples included successful lobbying and thus national acceptance of a new PMTCT manual with a chapter on family planning, coordination with the reproductive health unit, ability of the MTCT technical body to serve as an advocacy group, a move to mobilize resources from HIV/AIDS to strengthen related reproductive health services, and dedicating more resources in general since family planning is considered a priority.

Another factor facilitating increased attention to the integration of family planning and PMTCT is that many PMTCT stakeholders working both nationally and internationally have a background in reproductive health, including family planning. This background suggests not only technical knowledge in family planning, but also an interest in meeting reproductive health aims alongside meeting HIV objectives. For example, in Cameroon, one of the national stakeholders for PMTCT was "one of the first people in Cameroon to support family planning services beginning in 1986. Under his leadership, family planning services are integrated into the MCH program" as well as at all of their PMTCT sites. He is committed to seeing family planning and HIV issues integrated. "My goal is that if you go to the family planning clinic, you do not go home without HIV/AIDS messages. And if you go to ANC, you should hear about family planning."

\section{CONCLUSIONS/RECOMMENDATIONS}

\section{Integrate family planning support and services targeted to the needs of HIV-positive women into PMTCT services.}

Particularly in low contraceptive and high HIV prevalence settings, family planning within PMTCT program is addressed by parallel, not integrated, family planning services and often not tailored to meet the needs of HIV-positive women. In settings such as Uganda and Kenya where family planning use is still far from universal, HIV infection and HIV stigma are prevalent, and resources are stretched, we found that family planning is almost always available to women using PMTCT services but generally there is little additional effort to meet the needs of HIV-positive women. In these settings, family planning is one of many issues addressed in PMTCT counseling during the antenatal period. This is often a challenging moment for providing family planning counseling as pregnant women have more immediate concerns about their pregnancy, delivery, and care of the newborn. Moreover, HIV-positive women are pre-occupied with coping with the information that they are infected. Yet, family planning counseling in the antenatal period-as part of PMTCT counseling - gives women the option to choose post-partum methods such as tubal ligation. Follow-up in the post-natal period, particularly in high prevalence settings, is within general family planning services where providers may not even be aware of clients' family planning status.

In contrast, some programs such as in the Dominican Republic and Thailand have very targeted family planning components within their PMTCT services where they offer 
HIV-positive women a particular method-sterilization. This reflects the much lower volume of clients which allows them to devote a team to PMTCT, the greater resources to offer caesarean and a concurrent tubal ligation, the fact that it is appropriate and acceptable to provide a female sterilization in the immediate post-partum period (when other methods may interfere with breastfeeding or are coitus specific at a time when many women have not yet resumed sexual intercourse) and the generally high acceptance of sterilization in the country.

This review suggests that PMTCT programs will be more successful in promoting effective contraceptive use among their clients if the family planning counseling and services are integrated into the PMTCT services rather than offered as a parallel service. Family planning counseling for HIV-positive women must be sensitive to the needs of HIV positive women including their right to make an informed decision about having anther child or not and their desire to involve their male partner. The emphasis would vary depending on the setting but family planning counseling should help HIV-positive women introduce condoms to their partners, address fears related to hormonal methods, and/or support for adoption of permanent methods.

\section{Build on positive attitudes towards condoms among HIV-positive women and involve men to promote dual protection.}

Important findings from this review and the Horizons studies are the positive attitudes and growing use of condoms by HIV-positive women. HIV-positive women view condoms as safe for their health and unlikely to interact with their HIV infection. They provide protection from re-infection and from STIs that may compromise their health as well as unwanted pregnancy. They are also perceived as available, unlike other methods, which regularly experience stock-outs, and cheap even if they have to be purchased. The major obstacle to their use is getting the concurrence of their male partners.

PMTCT programs need to continue to address involving men, providing them with information, and encouraging them to get tested. Partner support will enhance the effectiveness of a number of components of PMTCT programs. What this review highlighted is the strong interest by HIV-positive women in using condoms and the refusal of the partner or her fear of his partner's reaction being the major obstacle. Important steps to gaining his cooperation include safely disclosing her HIV status and the partner being tested. Counseling HIV-positive women on condom use should go beyond the advantages and disadvantages of the method and mechanics of its use and also address whether and how a woman can disclose her HIV status and how to encourage her partner to get an HIV test.

PMTCT programs should also offer female condoms that allow some women to use an effective barrier method possibly without the knowledge of her partner. Finally, PMTCT programs should offer counseling and supplies of emergency contraception as a back-up for condoms to enhance their effectiveness. 


\section{Reduce loss to follow up in the postnatal period by improving mechanisms for post- natal follow-up and offering a continuum of care for HIV-positive women.}

In many settings, a large proportion of women do not return for postnatal follow up. This is especially challenging for family planning since most programs offer contraceptive methods in the postnatal period. Putting more emphasis on family planning counseling for HIV-positive women and ensuring that women had made a decision about a contraceptive method in the antenatal period would reduce the dependence on having to re-establish contact after delivery.

Post-natal family planning support targeted to the needs of HIV-positive women can be offered by PMTCT program staff or peer counselors or buddies. The M2M2B project in South Africa provides peer support for HIV-positive women identified in prenatal care, including the selection and follow up of a family planning method. Also, Uganda is piloting a post-natal peer support program with the objective of increasing family planning use among HIV-positive women. Health systems should also develop mechanisms for confidentially informing family planning providers about a client's HIV status in order to ensure a continuum of care. Finally all PMTCT-Plus programs should offer family planning.

\section{National and international leadership to integrate family planning as an essential component of PMTCT programs is bearing fruit and should be continued}

There is growing awareness regarding the need to emphasize family planning within PMTCT programs at many different levels and the results can be seen in growing attention to family planning services as an essential component of preventing vertical transmission and a means to reducing the number of HIV infected infants.

At the national level, although PMTCT and family planning are often managed in different divisions, national level health officials and stakeholders have identified the need for coordination. Stakeholders in some countries are communicating on a regular basis. This has been facilitated by the PMTCT technical group, which has representatives from both divisions as well as by advocates who are bringing people together.

At an international level, UN agencies have provided leadership for instance by defining four strategies to reduce vertical transmission. Specific guidelines about family planning would help in articulating how national programs may continue to develop the family planning component within PMTCT programs. As part of this, there should be continued dialogue about the issue of whether or not or the extent to which programs should be recommending HIV positive women to select a family planning method in order to avoid future pregnancies or supporting them to implement their reproductive health desires. Greater consensus about this issue, and clear recommendations from the UN agencies may help guide countries in developing their national policies. 
Donor agencies also play a significant role in determining the extent to which family planning is prioritized within PMTCT programs. Funding flows to support family planning counseling and services as well as donors requesting measurable progress would bring about increased attention to family planning.

Maintaining international leadership and supporting national leadership are important elements for ensuring that PMTCT providers and programs can continue to build on the various strengths identified in this review. 


\section{$\underline{\text { References }}$}

Achécar, M. et al. 2003. Encuesta Demográfica y de Salud: ENDESA 2002. Calverton MD: MEASURE DHS+/ORC MACRO.

Lallemant, C. et al. 2004. "Sterilization in HIV infected women in Thailand," paper presented at the Conference of the Population American Association, Boston, 1-3 April, 2004.

Rutenberg, N., Baek C., Kalibala S., Rosen J. 2003. Evaluation of United Nationssupported pilot projects for the prevention of mother-to-child transmission of HIV. New York: UNICEF and Population Council.

WHO. 2002. Strategic Approaches to the Prevention of HIV Infection in Infants: Report of a WHO meeting. Morges, Switzerland, 20-22 March. Geneva: WHO. 


\section{Appendix A}

\section{Questions for National Program Managers}

\section{$\underline{\text { Policy }}$}

If you have a national guideline for PMTCT, is FP discussed in the guideline?

Is there a family planning expert on the MTCT coordinating body?

Can the MTCT coordinating body or individuals in leadership positions bring anything to bear such as advocacy/leadership or resources to reinforce family planning as a method to PMTCT?

\section{Training}

Is family planning training provided during the PMTCT training?

If so, how much time is allocated to FP?

What is the content of the FP training?

\section{$\underline{\text { Communications }}$}

What are the main messages of the PMTCT communications program?

Is family planning mentioned in the communications message that goes out to communities? If yes, what is said? And in what form (mass media, IEC materials, drama groups, etc.)?

\section{$\underline{\text { Programs }}$}

In your PMTCT program, do you have a FP indicator? If so, what is it?

Have family planning stock outs been a problem? If so, can you describe?

Are there human resources available to place greater emphasis on FP or are they already overstretched?

Have you heard of innovative program strategies or models that emphasize FP within or integrate FP into PMTCT programs? 


\section{Questions for International Program Managers}

\section{$\underline{\text { Programs }}$}

What are your organizational guidelines for family planning within PMTCT programs?

For the programs that you are familiar or involved with, what is happening on the ground with FP and PMTCT?

In your PMTCT program, do you have a FP indicator? If so, what is it?

Are condoms offered at sites? If so, for HIV prevention, family planning, or both?

Have family planning stock outs been a problem? If so, can you describe?

Are there human resources available to place greater emphasis on FP or are they already overstretched?

Have you heard of innovative program strategies / models that emphasize FP within or integrate FP into PMTCT programs?

\section{$\underline{\text { Communications }}$}

What are the main messages of the PMTCT communications program?

Is family planning mentioned in the communications message that goes out to communities? If yes, what is said? And in what form (mass media, IEC materials, drama groups, etc.)?

\section{Questions for Providers and Managers on Site}

At your site, is there any protocol about what to say regarding FP and PMTCT? If yes, what is it?

Are FP counseling and services provided at the PMTCT site? If no, can you explain why not? Are clients referred to another site? How is the referral system organized?

If yes, where - same building, adjacent building? How are FP counseling and services organized at the PMTCT site?

Do PMTCT clients receive FP counseling and/or services as part of the PMTCT program? If so, when does this occur (antenatal and/or postnatal)?

Who provides family planning counseling and services at the PMTCT site? 
Does the same provider deliver FP services as well as PMTCT services?

What methods of FP do you have available on site? Which ones are most popular?

Are condoms offered at the site? If so, for HIV prevention, family planning, or both?

Have stock outs been a problem? If so, can you describe?

Do clients pay for FP contraceptive methods?

What do you hear people in your community say HIV positive women should do regarding childbearing or contraception? Has the availability of PMTCT services changed what people are saying?

What do HIV positive women say about their desired family size / intent for another pregnancy?

What do HIV positive women say about contraception? What do they say about specific methods: are they concerned about HIV infection (re-infecting themselves or protecting partner) and/or considering or using contraception as means to prevent pregnancy?

Are HIV issues brought up by clients during FP counseling? If so, what kinds of issues?

Do you know the client's HIV status when you are providing FP counseling? If so, does that affect what you say to the client? If yes, how?

Obtain family planning service statistics if available. 

Appendix B
International Program Managers
Name
Organization
Ms. Nicole Buono
Elizabeth Glaser Pediatric AIDS Foundation
Dr. Lynn Collins
UNFPA
Dr. Janet Kayita
Family Health International
Dr. Justin Mandala
Family Health International

\section{Country Level: National Program Managers and Stakeholders}

\section{Name}

\section{Brazil}

Dr. Ana Lucia Vasconcelos Brazilian National PMTCT Program

\section{Cameroon}

Dr. Anne Nlend

Dr. Tih Pius Muffih

Drs. Thomas and Edith

Welty

\section{Dominican Republic}

Dr. María Isabel Tavarez

Dr. Fátima Guerrero and Dr.

Osvaldo Lorenzo

Judith Timyan

\section{India}

Dr. Ranjit Virk

Mr. Arun Baroka

Dr. Neeru Bhatia

Dr. R.K. Batra

Dr. Kamal Batra

Dr. Bir Singh

Dr. Prakash Gurnani

\section{Organization}

Ministry of Health

Cameroon Baptist Convention Health Board

Cameroon Baptist Convention Health Board

Ministry of Health, Direccion General de Control Infecciones de Transmision Sexual

Consejo Presidencial del SIDA

Family Health International

National AIDS Control Organization (seconded from UNICEF), New Delhi

Government of Delhi - Ministry of Health \&

Family Welfare and Delhi State AIDS Control Organization, New Delhi

Delhi State AIDS Control Organization, New

Delhi

Department of Family Welfare, New Delhi

Health and Family Welfare Training Center, New

Delhi

UNICEF New Delhi

UNICEF Mumbai 


\section{Kenya}

Dr. Cherutich

Dr. Kahindo

Mr. Kilonzo

Ms. Lucy Njema

Dr. Solomon

Namibia

Mr. John Howson

\author{
NASCOP (National AIDS and STD Control \\ Programme) \\ Family Health International \\ Kenya AIDS NGO's Consortium \\ Christian Heath Association of Kenya \\ Division of Reproductive Health
}

Health Communications Partnership

Center for Communication Programs

Johns Hopkins Bloomberg School of Public

Health

Mothers 2 Mothers $2 \mathrm{Be}$

\section{South Africa}

Dr. Mitchell Besser

\section{Thailand}

Ms. Pornsinee Amornwichet Ministry of Public Health

\section{Uganda}

Dr. Saul Onyango

Ministry of Health

Dr. Mbonye

Reproductive Health Division

Dr. Fred Nuwaha

Elizabeth Glaser Pediatric AIDS Foundation

Ms. Esther Agali, Dr. Susan

Mukasa, Ms. Alison

Mobley, and Ms. Mabel

Namwabira

Ms. Linda Andrews
Population Services International

Population Leadership Program / Elizabeth

Glaser Pediatric AIDS Foundation

\section{Site Visits}

Location

Name

Dominican

Republic

Santo

Domingo

Santo

Domingo
Dr. Jose Schuoerer

Ms. Bélgica Garabito,

Ms. Lucia Lara

Hernández, Ms. Verónica

Sánchez
Site

Hospital Materno Infantil San

Lorenzo

Hospital Maternidad Nuestra Senora

La Altagracia 


\begin{tabular}{|c|c|c|}
\hline \multicolumn{3}{|l|}{ India } \\
\hline Mumbai & $\begin{array}{l}\text { Dr. Asha Dalal } \\
\text { Dr. Anand Pawal } \\
\text { Dr. Surpreet Magi }\end{array}$ & B.Y.L Nair Hospital \\
\hline Mumbai & $\begin{array}{l}\text { Dr. Rekha Daver, } \\
\text { Dr. Jaspal Malhotra } \\
\text { Dr. Matin Quadri } \\
\text { Ms. Arsharan Malhotra } \\
\text { Ms. Nirmala Wakode } \\
\text { Ms. Vidya Raokhande } \\
\text { Ms. Archana Kumble }\end{array}$ & $\begin{array}{l}\text { Grant Medical College and Sir JJ } \\
\text { Group of Hospitals }\end{array}$ \\
\hline Mumbai & $\begin{array}{l}\text { Dr. Vijay Bhadwar } \\
\text { Ms. Bhakti } \\
\text { Mr. Nishant }\end{array}$ & $\begin{array}{l}\text { Lokmanya Tilak Municipal Medical } \\
\text { College and General Hospital }\end{array}$ \\
\hline \multicolumn{3}{|l|}{ Kenya } \\
\hline Kibera & Ms. Pamela Onduru & $\begin{array}{l}\text { KICOSHEP Clinic (Kibera } \\
\text { Community Self-Help Programme) }\end{array}$ \\
\hline Kibera & Ms. Mercy Atieno & KICOSHEP Clinic \\
\hline Nairobi & Ms. Wambugu & $\begin{array}{l}\text { Kenyatta National Hospital ANC } \\
\text { Clinic }\end{array}$ \\
\hline Nairobi & Dr. Ong'ech & $\begin{array}{l}\text { Kenyatta National Hospital ANC } \\
\text { Clinic }\end{array}$ \\
\hline \multicolumn{3}{|l|}{ Thailand } \\
\hline $\begin{array}{l}\text { Chiang Mai } \\
\text { Province }\end{array}$ & Name not obtained & Doi Saket District Hospital \\
\hline $\begin{array}{l}\text { Chiang Mai } \\
\text { Province }\end{array}$ & Name not obtained & Sansai District Hospital \\
\hline $\begin{array}{l}\text { Nakhon } \\
\text { Panom } \\
\text { Province }\end{array}$ & Ms. Weawta Arnad & Nakhon Panom Provincial Hospital \\
\hline \multicolumn{3}{|l|}{ U ganda } \\
\hline Jinja & Dr. Agel Akii Yovan & Jinja Hospital \\
\hline Jinja & Ms. Loy Mudondo & Jinja Hospital \\
\hline Jinja & $\begin{array}{l}\text { Ms. Otim Kyebawa } \\
\text { Tappy }\end{array}$ & Jinja Hospital \\
\hline Mukono & Ms. Ruth Kawesa & Mukono Health Center IV \\
\hline Mukono & Ms. Anna Kazimoto & Mukono Health Center IV \\
\hline Kawolo & Ms. Betty Nalumasi & Kawolo Hospital \\
\hline Kawolo & Ms. Fatuma Nakiseka & Kawolo Hospital \\
\hline Kawolo & Ms. Josephine Waswa & Kawolo Hospital \\
\hline
\end{tabular}


